\title{
Experiencias de relegación urbana post-desastre. El caso de los damnificados del gran incendio de Valparaíso 2014 ${ }^{1}$
}

Post-disaster urban relegation experiences. The case of the victims of the great fire in Valparaíso 2014

\author{
Luis Campos Medina \\ Víctor Suazo Pereda \\ Andrea Cárdenas Piñero \\ Universidad de Chile, Chile
}

\begin{abstract}
RESUMEN Tras el mega incendio de 2014 que afectó los cerros de Valparaíso, diversos habitantes fueron reubicados en otras localidades de la región en el marco del proceso de reconstrucción. El presente artículo explora las experiencias de relocalización de un grupo de familias empobrecidas en la ciudad de Villa Alemana, cuyos relatos y significaciones evidencian procesos de relegación social y urbana. A partir de una investigación cualitativa desarrollada durante dos años junto al grupo de población relocalizada - que consideró entrevistas en profundidad, entrevistas en movimiento y observación participante - se argumenta que, en el contexto de una política habitacional viviendista como la chilena, la relocalización post-desastre tiene como resultado agudizar los efectos subjetivos nocivos derivados de la condición de damnificado. Ello se evidencia en cuatro dimensiones principales: (1) sentimiento de abandono del Estado; (2) estigmatización socio-territorial; (3) sociabilidad barrial; y (4) merma del capital espacial. Finalmente, se concluye en torno al daño subjetivo producido por los procesos de relegación post-desastre y su vínculo con la política pública de reconstrucción.
\end{abstract}

\footnotetext{
1. Artículo de Investigación Financiado por el Programa de apoyo a la Productividad Académica PROA VID 2018, de la Universidad de Chile. El equipo agradece el apoyo del Centro de Estudios de Conflicto y Cohesión Social (ANID/FONDAP/151300o9) y del Fondo Nacional de Desarrollo Científico y Tecnológico (FONDECYT INICIACION 11140356).
} 
PALABRAS CLAVE Relegación urbana; desastres; subjetividad; Valparaíso.

ABSTRACT After the 2014 mega fire that affected the hills of Valparaíso, several inhabitants were relocated to other localities within the region, as part of the reconstruction process. This article explores the experiences of relocation of a group of impoverished families in the city of Villa Alemana, whose stories and meanings show processes of social and urban relegation. Based on a qualitative research conducted over two years with the relocated population group - which considered in-depth interviews, moving interviews and participant observation - it is argued that, in the context of a viviendista housing policy like the Chilean one, the post-disaster relocation has as result the sharpening of the subjective harmful effects derived from the condition of victim. This is evident in four main dimensions: (1) feeling of abandonment of the State; (2) socio-territorial stigmatization; (3) neighborhood sociability; and (4) diminishing of space capital. Finally, it concludes on the subjective damage produced by the processes of post-disaster relegation and its link with the public policy of reconstruction.

KEY WORDS Urban relegation; disasters; subjectivity; Valparaíso.

\section{Introducción}

El objetivo de este artículo es explorar las formas en las que se vive y experimenta la relegación urbana por parte de habitantes pobres en la ciudad de Villa Alemana. Este, sin embargo, no es cualquier caso de relegación urbana, sino que tiene la particularidad de producirse en un contexto de reconstrucción post-desastre, lo que, como mostraremos, tiene como efecto agudizar las consecuencias subjetivas nocivas derivadas de la condición de damnificado.

Nos concentraremos en cuatro efectos principales: en primer lugar, el sentimiento de abandono por parte del Estado que experimentan las personas afectadas. En segundo lugar, la activación de una dinámica de estigmatización socio-territorial que vivencia la población relocalizada. En tercer lugar, el desarrollo de un tipo de sociabilidad barrial caracterizado por la violencia, la desconfianza y la inseguridad, y; en cuarto lugar, la merma en el capital espacial del grupo estudiado.

Desde la perspectiva que aquí adoptamos, los procesos de reconstrucción postdesastre se han convertido en dinamizadores de la transformación urbana de corte neoliberal (Theodore et al., 2009), a través de la puesta en acción de un conjunto de iniciativas que incluye asociaciones público-privadas, adecuación circunstancial de instrumentos de política de vivienda a los procesos enfrentados $\mathrm{y}$, muy importante para entender la dimensión subjetiva de la relegación, urgencia en la atención de víctimas y damnificados. 
No obstante, y pese a la magnitud y relevancia de estas intervenciones de shock, que buscan capitalizar el desastre (Klein, 2007), desde los estudios territoriales no se ha prestado suficiente atención a los efectos subjetivos involucrados en los procesos de relocalización (Angelcos et al., 2020). En este sentido, buscamos avanzar en la senda marcada por Contreras y Arriagada (2016) con la noción de "reconstrucción exclusionaria", que indica que los procesos de reconstrucción generan formas de desplazamiento a espacios más alejados del centro, de los equipamientos urbanos y de las redes sociales de los grupos afectados por los desastres, siendo nuestro propósito dar mayor precisión y profundidad al análisis de las consecuencias subjetivas que tienen dichas intervenciones.

Vale decir, interesa enfocar nuestro análisis, no en fuerzas abstractas o en ordenamientos geográficos inaprehensibles para los individuos, sino que en aquellos efectos que adoptan un cariz vivencial y que dan forma a las experiencias de los individuos de modo constante, quedando inscritas en sus habitus (Bourdieu, 2001) y en sus cuerpos (Scribano, 2007), modelando sus vidas cotidianas (Reyes et al., 2016).

Participamos de una concepción amplia de la subjetividad en la que ella es concebida como un entramado complejo que incluye una narrativa de auto-comprensión individual que posibilita la relación con los poderes imperantes en una sociedad (Angelcos et al., 2020; Rivera y Campos, 2019), pero también incluye una forma de inscripción espacial, que posibilita esa auto-comprensión y que se origina en el habitar estable de un territorio, donde los humanos hallan posibilidades de encuentro, interacción y sociabilidad con otros (Butler y Athanasiou, 2017). Porque la subjetividad pasa por "prácticas regulatorias vinculadas a las condiciones de localización, desplazamiento y emplazamiento, prácticas que producen o constriñen la inteligibilidad humana" (Butler y Athanasiou, 2017, p.34).

Un elemento fundamental a tener en consideración en el caso de los procesos de relocalización post-desastre en Chile es que, de manera creciente, la intervención del Estado se caracteriza por su celeridad (Campos et al., 2018). En efecto, una condición para capitalizar el desastre es el actuar acelerado del aparato público en alianza con los actores de mercado, de modo de poder hacer frente a las "situaciones de excepción" y sacar rédito de la "oportunidad". La crisis generada por el desastre se vuelve el panorama idóneo para el actuar acelerado, concertado y sincronizado entre el Estado y el mercado, y producir, en el marco del proceso de reconstrucción, transformaciones urbanas que hubiese sido más lento implementar en contextos habituales.

Para el mercado de la vivienda, Bourdieu (2001) plantea que el Estado es el gran encargado de darle forma a la demanda, pero que, a su vez, los privados tienen una fuerte influencia sobre las políticas que diseña e implementa el Estado. Lo anterior se hace más patente en el Chile neoliberal caracterizado por la subsidiariedad del Estado y una política habitacional viviendista cuyo énfasis durante las últimas décadas, aun- 
que con matices recientes, ha estado en la producción masiva de unidades habitacionales. Consideramos que este elemento se agudiza en las situaciones de reconstrucción post-desastre donde el Estado, a través de instrumentos como los subsidios de reconstrucción, crea una demanda y, a través de procedimientos menos tipificados, contribuye a conectarla con la oferta de los privados (Rodríguez y Sugranyes, 2004). En ese sentido, postulamos que el actuar acelerado permite ocultar, dentro de la reconstrucción, transformaciones urbanas que implican situaciones potencialmente conflictivas, como es el desplazamiento de población de bajos ingresos.

Este fue el caso de la relocalización de población realizada en la Villa El Aromo, en la ciudad de Villa Alemana, puesto que 263 familias damnificadas luego del gran incendio del 12 de abril de 2014 en Valparaíso fueron instaladas en un conjunto habitacional que había sido originalmente edificado para ser vendido a familias de clase media-baja y que, al momento del desastre, se encontraba "disponible" para ser utilizado como solución a la tragedia vivida por dichas familias.

A continuación, se revisa conceptualmente la articulación entre las nociones de desplazamiento, relegación y estigmatización, tendiendo puentes teóricos con la política de vivienda en el Chile contemporáneo. Luego, se exponen las características de esta investigación cualitativa basada en el estudio de un caso de población damnificada tras el mega incendio de Valparaíso, relocalizada en la ciudad de Villa Alemana. Posteriormente y basados en los relatos de la población relocalizada, se analizan cuatro dimensiones en las cuales experimentan la relegación urbana post-desastre. Finalmente, se exponen conclusiones de la investigación.

\section{Desplazamiento, relegación y estigmatización}

La producción urbana capitalista ha sido caracterizada por Janoschka (2016) como inherentemente orientada hacia el desplazamiento de población de bajos ingresos. No obstante, para este autor dicho desplazamiento no remite a un proceso puramente espacial, sino que se trata de un proceso complejo que debe ser comprendido simultáneamente como: (1) un proceso material de índole económica-financiera, dada por la aplicación de la racionalidad económica del mercado inmobiliario; (2) un proceso político, dado por la validez legal y política-administrativa del proceso del desplazamiento, donde el Estado cumple un rol fundamental; (3) un proceso simbólico, donde las subjetividades y relaciones de poder se manifiestan; y (4) un proceso psicológico, que se manifiesta como efecto en la escala individual de los desplazados y que se expresa en la forma de alienación o dislocación, entre otras.

Mediante la aplicación empírica de esta perspectiva se ha propuesto que el desplazamiento de población de bajos ingresos es un proceso intrínseco de la producción urbana capitalista (Campos et al., 2018), en la medida que constituye una herramienta que posibilita la captación de la rentabilidad del suelo, apoyándose en la variación 
temporal y espacial de las distintas externalidades. Campos et al. (2018), indican que los motores de este desplazamiento son la maximización acelerada de la plusvalía para los actores económicos y la injerencia activa e intervención maximizadora de la rentabilidad política, para el Estado y los actores políticos. De esto se deriva que los aspectos (1) y (2) indicados por Janoschka se encuentran fuertemente imbricados en el plano empírico.

En contextos de reconstrucción post-desastre, este proceso suele estar estrechamente vinculado a la producción de nuevos stocks habitacionales (Contreras y Beltrán, 2015; Inzulza y Cárdenas, 2017; Rasse y Letelier, 2013; Suazo, 2019). La destrucción material generada por el desastre condiciona la reparación y construcción de nuevas viviendas para dar cobijo a los damnificados, especialmente para la población de bajos ingresos, que suele ser la más afectada por las catástrofes. Al respecto, Delgadillo (2015) señala que los desastres socio-naturales son oportunidades para dinamizar el mercado inmobiliario y para "solucionar" el problema que afecta a los pobres que habitan las periferias urbanas mediante la implementación de "ayudas públicas".

En Chile, durante la dictadura cívico-militar, el Estado abandona su rol como ente proveedor de servicios básicos a la ciudadanía dando paso a un Estado subsidiario que delega su responsabilidad a la iniciativa privada (Borsdorf et al., 2008). A la fecha, la política de vivienda en el Chile neoliberal ha consistido, fundamentalmente, en combatir el déficit cuantitativo de vivienda a través de la provisión masiva de vivienda social mediante subsidios habitacionales. En consecuencia, se configura una política habitacional donde tanto el suelo como la vivienda son considerados bienes de consumo transables en el mercado, donde el Estado ha adquirido una función meramente subsidiaria y donde el mercado privado controla la intervención, las tipologías y la localización de la vivienda social (Rodríguez y Sugranyes, 2004).

En este sentido, el principal mecanismo de reconstrucción post-catástrofe implementado en Chile se basa en la entrega de subsidios habitacionales regulares para los damnificados, priorizando la reconstrucción material de viviendas por sobre otras dimensiones del hábitat residencial que se ven afectadas con el desastre. Esto se ha traducido en un dispositivo de financiamiento público que apoya económicamente a los beneficiarios, subvenciona la demanda de vivienda, garantiza la oferta habitacional producida por empresas constructoras privadas, al mismo tiempo que asegura la participación de los bancos que financian los créditos de los postulantes a subsidios (Rodríguez y Sugranyes, 2004).

En consecuencia, la dirección de los procesos de reconstrucción queda en manos de desarrolladores inmobiliarios privados, quienes, en base a criterios de rentabilidad económica, deciden dónde localizar la oferta de vivienda para grupos de bajos ingresos. Así, resulta más atractiva la construcción de conjuntos de vivienda social en las periferias de las ciudades, en aquellos sectores donde el suelo es más barato 
y donde los equipamientos, servicios, infraestructuras y redes de transporte suelen ser precarios e incluso, inexistentes (Ducci, 1997). En este sentido, diferentes actores dominantes aprovechan la oportunidad abierta por el desastre socio-natural para desplegar sus posibilidades de negocios, para reordenar la estructura socio-territorial de las ciudades o, simplemente, para reforzar su control territorial (Blanco y Apaolaza, 2016).

Refiriéndose al caso de Talca post-terremoto de 2010, Letelier y Boyco (2011) señalan que en el proceso de reconstrucción importaron solo dos cosas: (1) incorporar un nuevo stock de suelo urbano a la actividad inmobiliaria; y (2) vincular, a través de los subsidios habitacionales estatales, la demanda de vivienda por parte de los damnificados con la oferta de vivienda barata producida por el mercado inmobiliario. Esto último se ha traducido en un masivo "desplazamiento subsidiario" de clases populares desde el centro histórico de la ciudad hacia la periferia (Inzulza y Cárdenas, 2017). Estos desplazamientos no solo se han producido desde áreas apetecidas por el capital inmobiliario, como son los centros históricos, sino que, incluso, desde áreas rurales hacia las periferias urbanas dado el sesgo neoliberal, centralista y urbano que han adquirido las políticas de reconstrucción, desconociendo las particularidades locales de los territorios y comunidades afectadas (Concha-Saldías et al.,2015; Micheletti et al., 2017; Micheletti y Letelier, 2016).

Por otra parte, los aspectos simbólicos y psicológicos son una consecuencia ineludible de la forma capitalista y neoliberal de desplazamiento, debido a que éste adopta la forma de la relegación y no de un simple movimiento en el espacio urbano (Campos et al., 2018). En efecto, como plantean Blanco et al., (2014), los desplazados "suelen ser obligados a dirigirse hacia lugares con menor accesibilidad, más lejanos a los empleos que ya tienen o a las áreas de empleo donde podrían encontrar trabajo, probablemente con menores alternativas de acceso a centros de servicios y desarmando las redes sociales tejidas en el barrio de residencia" (Blanco et al., 2014, p. 8). Esto equivale a decir que son trasladados a lugares que presentan las características para convertirse en espacios de frustración, de estigmatización y, más en general, de vivencia subjetiva del daño.

A este tipo de espacios Wacquant (2001) les ha llamado "territorios de relegación", los que se caracterizan por una lógica de concentración de población precaria en sectores de la ciudad difícilmente abordables por la política pública y sobre los cuales recae una fuerte estigmatización social, pero que, además, ya no cuentan con la presencia estable de sindicatos ni de organizaciones comunales, comenzando a desaparecer la mutualidad y la actividad colectiva, para dar espacio a estrategias de distanciamiento que erosionan la solidaridad social. Como resulta evidente, desde la perspectiva de este autor esta situación de privación material, marginación política y merma sociocultural que afecta a dichos territorios encuentra en el Estado, en asocia- 
ción con actores privados, a su principal agente causal, puesto que Estado y mercado suelen retirarse de forma conjunta de los lugares dejando a sus habitantes a su suerte.

Las consecuencias subjetivas de lo anterior son enormes, en la medida que, como indica Bourdieu (2001), la definición de la localización en el espacio urbano constituye una de las expresiones más directas y naturalizadas de la violencia propia a un orden social y, además, una de las mayores fuentes de violencia simbólica, vale decir, de aquella violencia sutil que se expresa como dominación internalizada y que implica el surgimiento de una autocomprensión del sujeto adecuada a los términos que organizan la dominación social (Bourdieu, 1992). En consecuencia, la estigmatización social de estos "territorios de relegación" se transforma rápidamente en autoestigmatización por parte de sus habitantes.

En sintonía fina con esta perspectiva teórica, Wacquant (2001) plantea que la situación "deprimida de la economía y la ecología locales ejerce un efecto de desmoralización penetrante en los residentes (...) A decir verdad, las palabras "deprimente" y "desalentador" aparecen una y otra vez en las descripciones que ellos hacen de su entorno" (Wacquant, 2001, p. 138).

Algo similar constata Lapeyronnie (2014) en relación a la "economía moral de la discriminación" propia de los barrios populares de la banlieue francesa: el discurso de sus habitantes está marcado por la sensación de bloqueo a las posibilidades de realización, por el sentirse impedido de ser uno mismo y de poder realizarse, todo ello como efecto de la discriminación ejercida por la sociedad exterior al barrio, engendrando sentimientos de fatiga, fastidio y desidia.

Siguiendo a Wacquant, es posible plantear que la estigmatización que sufre la población de estos territorios de relegación estimula "prácticas de diferenciación y distanciamiento sociales internos que contribuyen a reducir la confianza interpersonal y socavar la solidaridad social local" (2001, p. 142) y que esas estrategias asumen tres formas principales: i) la evitación mutua; ii) la elaboración de "infradiferencias" o "microjerarquías" y, iii) el desvío del desprecio público hacia chivos expiatorios, tales como extranjeros, vendedores de droga o madres solteras (Wacquant, 2001).

Siguiendo a Lapeyronnie (2014), es posible plantear que la vivencia de la estigmatización estimula un fuerte sentimiento de injusticia que induce actitudes de hostilidad y de desconfianza hacia las instituciones y hacia las categorías sociales dominantes, de las cuales se sospecha que siempre buscan perjudicar a los más débiles. De acuerdo con esta descripción, la relegación urbana tiene como correlatos evidentes la desarticulación del tejido social local y problemas subjetivos de privación de los medios para hacer inteligible la propia experiencia.

Frente a esta situación, son diversas las experiencias en que los sujetos, con mayor o menor grado de éxito, buscan hacer frente a los procesos de desplazamiento y relegación en contextos de reconstrucción por medio de estrategias familiares (Rojas- 
Páez y Sandoval-Díaz, 2020) o estrategias colectivas que apelan a los capitales y recursos comunitarios de la población afectada (Larenas et al., 2015).

\section{Metodología}

En el plano metodológico, el material de base para este artículo surge de una investigación realizada entre los años 2015 y 2017 en los cerros afectados por el megaincendio de 2014 en la ciudad de Valparaíso, y en el seguimiento de un grupo de personas afectadas por dicho incendio y relocalizadas en un conjunto habitacional de la ciudad de Villa Alemana al que hemos denominado, para mantener el anonimato de las personas involucradas, Villa El Aromo.

Se seleccionó este caso por ser una de las soluciones más rápidas que se dio a los damnificados, ya que, a cuatro meses de ocurrido el incendio, el conjunto se encontraba habitado. No obstante, a pocas semanas de instalarse en sus casas, el conjunto cobró relevancia pública al aparecer en reportajes de prensa debido a los daños causados en las casas por las lluvias del invierno y el descontento en que se encontraban sus habitantes.

La investigación adoptó una orientación etnográfica e involucró la aplicación de diversas técnicas de producción de información: entrevistas en profundidad (10), recorridos comentados (15) y jornadas de observación (40). Además, efectuamos reuniones informales (10) y jornadas de intercambio con los habitantes de Villa el Aromo (2).

\section{Tabla 1}

Pseudónimos de entrevistados.

\begin{tabular}{|c|c|}
\hline Entrevista & Pseudónimo \\
\hline Entrevista 1 & Pedro \\
\hline Entrevista 2 & Fernanda \\
\hline Entrevista 3 & Josefina \\
\hline Entrevista 4 & Carolina \\
\hline Entrevista 5 & Paola \\
\hline Entrevista 6 & Elena \\
\hline Entrevista 7 & Carmen \\
\hline Entrevista 8 & Luisa \\
\hline Entrevista 9 & María \\
\hline Entrevista 10 & José \\
\hline
\end{tabular}

Fuente: Elaboración propia. 
El mecanismo para la realización de entrevistas, recorridos comentados y reuniones informales fue el contacto inicial de antiguos dirigentes vecinales de Valparaíso que intentaban adoptar un rol análogo en la nueva villa. A través de ellos se contactó a otros habitantes para realizar las distintas actividades previstas, a las que los y las vecinas accedieron con buena disposición. El material que se discute en este artículo proviene principalmente de las entrevistas en profundidad (10), las que fueron anonimizadas, para resguardar a las personas involucradas (ver Tabla 1).

\section{Resultados}

En el conjunto habitacional Villa El Aromo, ubicado en la ciudad de Villa Alemana, residen 263 familias damnificadas tras el mega incendio de 2014 en la ciudad de Valparaíso. Estas familias provienen de los cerros afectados por la catástrofe, específicamente, de los cerros El Litre, La Cruz, Las Cañas, Mariposas, Merced, Ramaditas y Rocuant (ver Figuras 1, 2 y 3). Tradicionalmente, los cerros de Valparaíso han sido asociados a la autoconstrucción, la informalidad y a ser el lugar de habitación de grupos empobrecidos. De hecho, los residentes de Villa El Aromo pertenecen al primer y segundo quintil de vulnerabilidad, lo que corresponde a los grupos de población más vulnerables de la sociedad chilena actual. Asimismo, más del $80 \%$ de los residentes era no-propietario en sus cerros de proveniencia (ver Tabla 2, donde no-propietario incluye todas las categorías excepto las marcadas en gris: "propietario", "cedido" y "sucesión"). En este sentido, los residentes de Villa El Aromo se encontraban en una triple condición de vulnerabilidad social, a saber, eran pobres, no-propietarios de vivienda y damnificados del incendio.

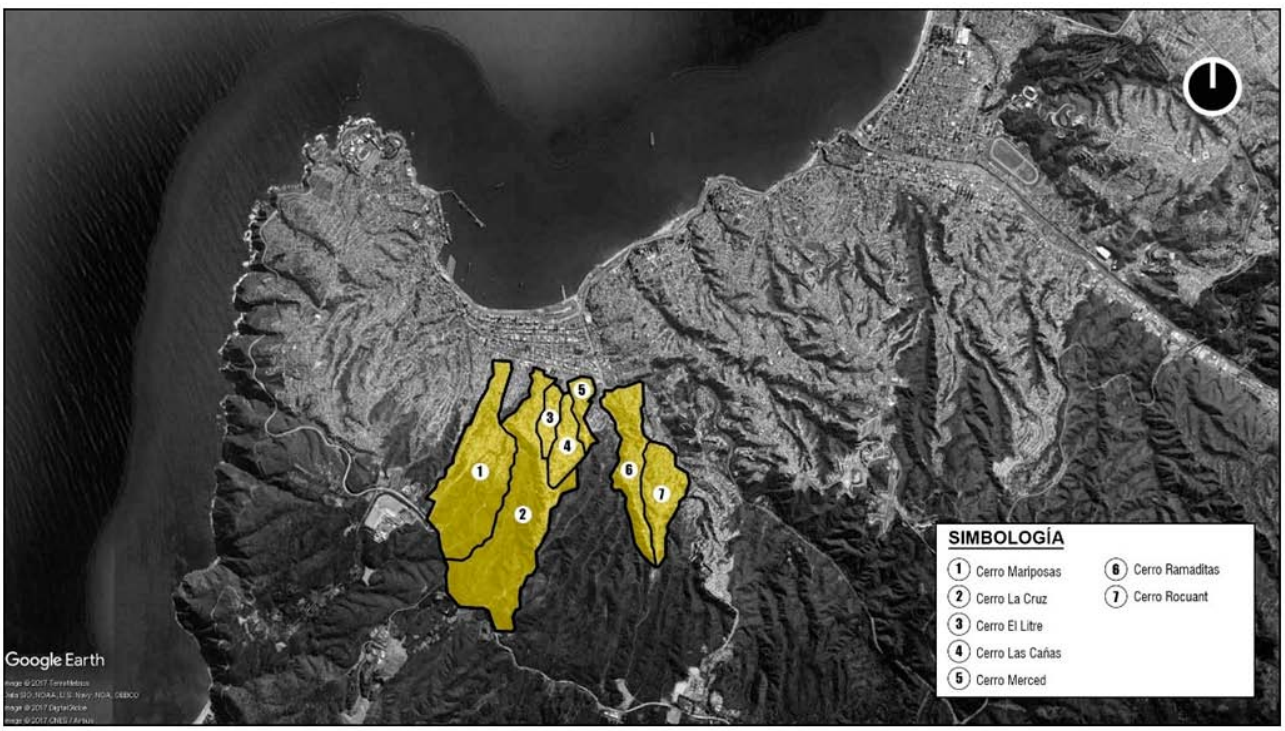

Figura 1. Cerros afectados por el incendio de 2014.

Fuente: Elaboración propia. 


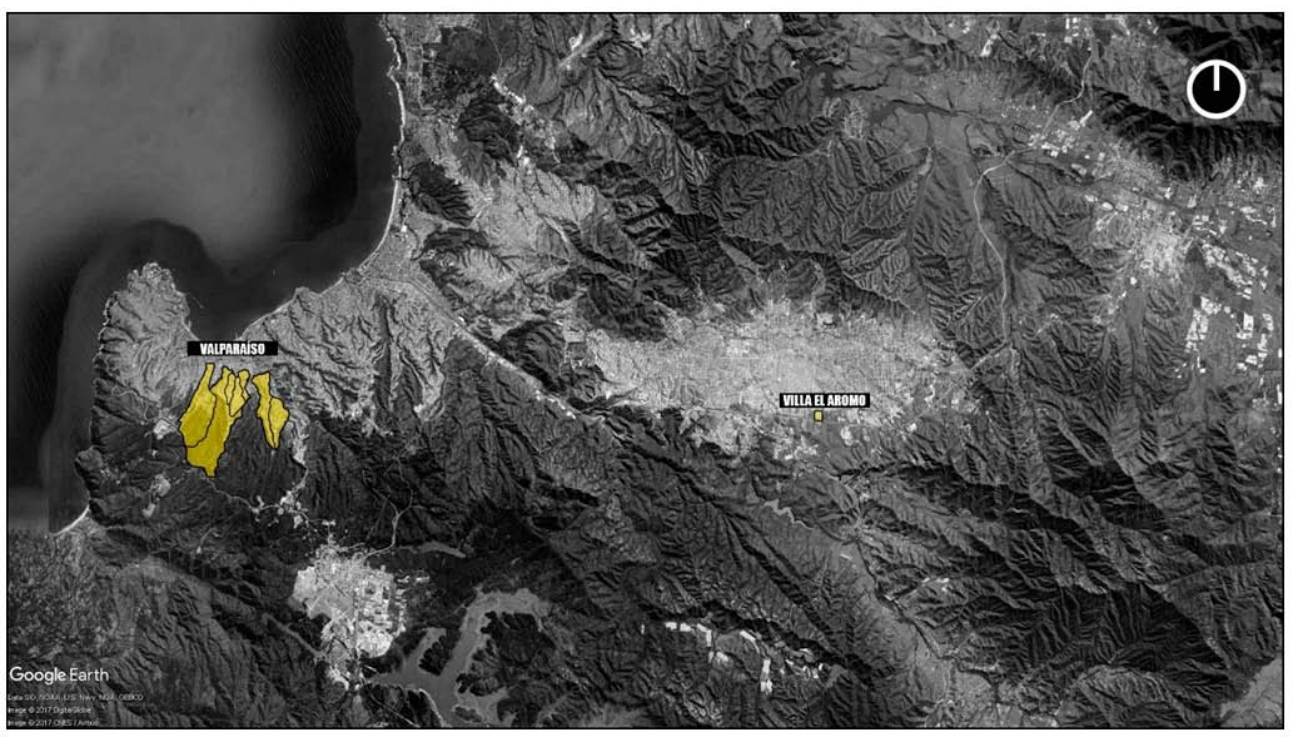

Figura 2. Localización regional del conjunto habitacional Villa El Aromo. Fuente: Elaboración propia.

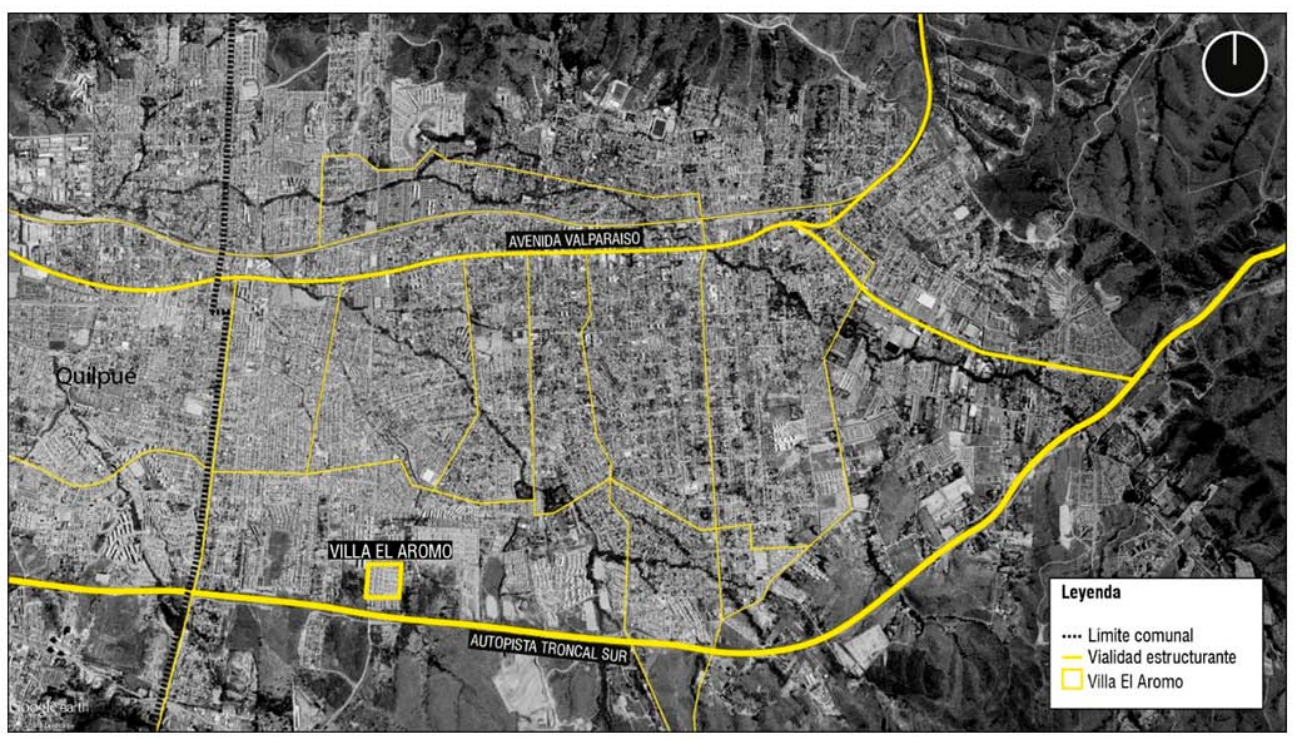

Figura 3. Localización del conjunto habitacional Villa El Aromo en la ciudad de Villa Alemana.

Fuente: Elaboración propia. 
Tabla 2

Situación de vivienda de los habitantes de Villa El Aromo, antes del mega-incendio de Valparaíso 2014.

\begin{tabular}{|l|c|c|}
\hline \multicolumn{1}{|c|}{ Calidad de Ocupación } & $\mathbf{N}^{\circ}$ beneficiarios & Porcentaje \\
\hline Allegado & 99 & $38 \%$ \\
\hline Arrendatario & 32 & $12 \%$ \\
\hline Ocupación Irregular & 77 & $29 \%$ \\
\hline Sucesión & 32 & $12 \%$ \\
\hline Cedido & 8 & $3 \%$ \\
\hline Propietario & 9 & $3 \%$ \\
\hline Usufructuario & 1 & $0 \%$ \\
\hline Sin Información & 1 & $0 \%$ \\
\hline Otro & 4 & $2 \%$ \\
\hline Total general & $\mathbf{2 6 3}$ & $\mathbf{1 0 0 \%}$ \\
\hline
\end{tabular}

Fuente: Elaboración propia.

Para gran parte de los sujetos entrevistados la reconstrucción tras el mega incendio de 2014 en Valparaíso se experimenta y se percibe como un proceso de relegación social y urbana. El "desplazamiento subsidiario" hacia la ciudad de Villa Alemana (Inzulza y Cárdenas, 2017), los mecanismos mediante los cuales se gestó el proceso, el actuar del Estado e instituciones públicas y privadas, sumado a la relocalización en un territorio desconocido, incrementa la experiencia de un tratamiento descuidado en el proceso de reconstrucción.

En los relatos de los habitantes del Villa El Aromo identificamos cuatro dimensiones en las que se experimenta la relegación: i) sentimiento de abandono por parte del Estado; ii) activación de una dinámica de estigmatización socio-territorial; iii) desarrollo de un tipo de sociabilidad barrial caracterizado por la violencia, la desconfianza y la inseguridad, y; iv) merma en el capital espacial. A continuación, pasamos a revisar en detalle cada uno de ellos.

\section{Abandono del Estado}

La tónica de la acción del Estado en el proceso de reconstrucción se caracterizó por la celeridad para dar solución habitacional a los damnificados en Villa El Aromo, ya que, a sólo cuatro meses de ocurrido el incendio, las viviendas fueron entregadas a los beneficiarios mediante subsidios habitacionales. "Estábamos todos contentos con nuestro subsidio, pero no sabíamos lo que iba a venir después" (Pedro), nos comenta un vecino de Villa El Aromo. El Estado se hace presente y actúa en la inmediatez de la catástrofe y en el proceso de reconstrucción, pero en etapas posteriores se desentien- 
de de los damnificados y de su inserción en el nuevo territorio. Como nos comenta una entrevistada, "gracias a Dios tenemos una casa, tenemos donde vivir, pero no es la felicidad que nosotros queríamos" (Fernanda).

En efecto, una vez entregada la vivienda, los damnificados de Villa El Aromo sienten que han sido abandonados por el Estado. Como señala un entrevistado, "a nosotros nos acarrearon y nos botaron como oveja sin pastor" (Pedro). Otra vecina comenta que a "toda la gente quemá la tiraron pa acá (...) a otros [los tiraron] pa otros laos" (Josefina). Ambos relatos sugieren un tratamiento descuidado y carente de sensibilidad recibido por parte del Estado. Las alusiones a ser "botados" o "tirados" en Villa El Aromo exacerban la condición de abandono y el tratamiento poco digno por parte de las autoridades, lo que, en palabras del mismo entrevistado recién mencionado, se percibe como un "maltrato" y un tratamiento "poco humano ante una tragedia" (Pedro).

...esto es lo que hicieron con la pobre gente: las pescaron, las tiraron como perro. Por eso nosotros estamos súper irritados con la gente de allá, del puerto, las autoridades (...) Todavía la gente guarda rencor con las autoridades, por el maltrato, que... poco humano que hubo ante una tragedia (Pedro).

Sin embargo, ese abandono no solo se produce por parte de las instituciones del Estado a nivel central, sino que también en otras escalas y por otros actores. Los entrevistados comentan que, tras la ocurrencia del incendio, diversas figuras públicas vinculadas a la política estuvieron trabajando en los cerros y que, incluso, prometieron acompañarlos a solucionar su situación de damnificados. Sin embargo, indican que tras pasar la inmediatez del incendio y "después de que se apagaron las cámaras" -como indicó una entrevistada- estas figuras políticas se desentendieron de ellos, lo que contribuye a incrementar su percepción de abandono.

Esa percepción de abandono Estatal se materializa también a nivel de gobierno local. Una entrevistada comenta que, tras su arribo a Villa El Aromo, estuvieron meses sin que el servicio recolector de residuos domiciliarios pasara por la villa, labor que le corresponde a la Municipalidad de Villa Alemana. Nos indica que tuvieron que acudir a las oficinas de la Municipalidad en reiteradas ocasiones e, incluso, amenazar con una protesta callejera para conseguir acceder a un servicio básico como el aludido.

Otra arista relevada por los entrevistados remite a la inexistencia de un espacio de atención o acompañamiento psicológico otorgado por el Estado, a pesar de considerar que fueron afectados por una catástrofe de grandes proporciones, que implicó enormes pérdidas para todos ellos. Esta carencia contribuye a incrementar su percepción de abandono en el proceso de reconstrucción y, en la situación actual, se convierte en una dificultad para rearticular su vida cotidiana en el territorio de acogida. "Aquí jamás vino un psicólogo a hacerles un informe psicológico. Lo que 
nosotros vivimos, la catástrofe que fue...fue grande, pero a los niños tampoco nunca los trataron" (Fernanda).

En síntesis, en relación a la sensación de abandono por parte del Estado es necesario destacar que, en los procesos de reconstrucción post-desastre, las temporalidades involucradas en el tratamiento de los damnificados juegan un rol clave en las sensaciones de daño y sufrimiento. En un primer momento, asociado a la inmediatez del desastre, los sujetos afectados reciben atención muy rápida, tanto desde los medios de prensa, como de parte de las autoridades y las organizaciones no gubernamentales (Angelcos et al., 2020). Sin embargo, una vez resuelto el problema de la vivienda, se produce un proceso repentino de "desatención" y "olvido" de los damnificados. Lo anterior evidencia el carácter viviendista de la política habitacional chilena, especialmente en los procesos de reconstrucción ante desastres socio-naturales, en los que no se presta atención a las distintas aristas involucradas en la reinserción de los damnificados en el nuevo territorio.

\section{Estigmatización territorial}

Al poco tiempo de arribar a Villa El Aromo, sus habitantes experimentaron procesos de estigmatización socio-territorial. De acuerdo con sus relatos, estos procesos de estigmatización fueron experimentados en tres niveles y ejercidos por diversos agentes sociales.

En primer lugar, experimentaron la estigmatización por parte de otros habitantes de Villa Alemana, especialmente, de parte de residentes de sectores aledaños. Una entrevistada nos comentaba que a Villa El Aromo la llamaban despectivamente "la población de los quemados", una cruel denominación para quienes vivieron el sufrimiento de un incendio.

La gente de aquí ponía letreros que nosotros éramos delincuentes y cosas así. Un día hubo un incendio al otro lao de los departamentos. Uno ya pasó por eso, pucha, era un incendio y se veía grande. Nosotros fuimos a ayudar: "no, que no. Váyanse de aquí que vienen a robar". Entonces somos muy mal catalogaos toda la gente. Tú no podi' echar a todos al mismo saco porque sí, a lo mejor sí, se vino gente delincuente, gente que vende vicios y cosas así, pero todos no tenimos la misma... las mismas metas (Carolina).

Incluso, algunos de los habitantes de la villa relatan episodios de discriminación laboral asociada a su lugar de residencia y a su proveniencia desde Valparaíso, en la medida que la denominación de "porteños" posee una connotación asociada a lo delictual. "Somos mal mirados. No sé... “ ¿usted de qué lugar es?", “usted es de... ¡ah! 
De la población de los porteños", "no", me dijo, "no tengo trabajo para usted". Marginados totalmente" (Paola).

En la misma dirección, una vecina nos relató un episodio en el que funcionarios de una empresa de telefonía manifestaron el estigma que pesa sobre Villa El Aromo.

Estamos mal mirados en todos lados. Ayer no más, vino un caballero de [Empresa de Telefonía] (...) vino como a las cinco de la tarde y me dijo: "puede decirle a la compañera que le llegó visita porque después de las cinco yo no puedo estar acá”. Yo les dije: “por qué?”, le dije yo, “no”, me dijo, "porque ya llevamos seis camiones reventados. Aquí, en esta población, nos roban las escaleras. Tenemos seis camiones reventados en los vidrios, asaltados. Por favor, cualquier cosa que usted necesite de [Empresa de Telefonía], nuestros servicios, pida que sea en la mañana, porque en la tarde, después de las cinco de la tarde, no podemos andar por acá (Paola).

En segundo lugar, los habitantes de la villa declaran experimentar la estigmatización y discriminación por parte de algunas instituciones, tales como el municipio o establecimientos educacionales. En este caso, lidiar con el estigma se vuelve más complejo, debido a la potencia simbólica y performativa de instituciones que intervienen directamente en la vida cotidiana de las personas.

Hasta el alcalde a nosotros nos rechaza como porteños, porque nosotros somos una mala influencia para él...para el alcalde de acá de Villa Alemana. Uno va al municipio a renovar un subsidio familiar y es mal mirada (...) A los porteños no le dan ninguna preferencia (...) está muy mal mirado El Aromo.... Luego agrega lo siguiente: "la mujer porteña y el hombre porteño es mal mirado en la municipalidad de acá (Fernanda).

Sin embargo, esta estigmatización no sólo proviene desde agentes externos a Villa El Aromo, sino que también existen mecanismos de estigmatización y diferenciación interna entre sus propios habitantes, aspecto al que aludimos anteriormente, en la discusión conceptual, en términos de violencia simbólica e internalización de la dominación que redunda en la producción subjetiva del estigma. De acuerdo a los relatos de los habitantes de la villa, quienes suelen sufrir la estigmatización interna son aquellos residentes que provienen de asentamientos informales en los cerros de Valparaíso, quienes vivían en las llamadas "tomas de terreno". Así, mientras nos habla sobre la violencia y el narcotráfico en Villa El Aromo, Paola insinúa que son quienes

2. La expresión "porteño" tiene cierta ambivalencia, porque es utilizada por terceros para denostar a quien la aplican en los sentidos aquí indicados, pero, empleada para referirse a sí mismos, es, para muchos, motivo de identificación y orgullo. 
provienen de tomas de terreno los que efectúan los delitos: "la mayoría de las personas que están aquí son de tomas, del cerro Las Cañas, de arriba, alto. Todos esos eran... por eso yo le digo "la casualidad"' (Paola).

Estos habitantes suelen ser catalogados por sus propios vecinos como sucios, desordenados, conflictivos y violentos, algo que, en palabras de una entrevistada, sería "un sistema de vida que tienen ellos propio" (Paola). Al referirse a los vecinos que provienen de tomas de terreno, Fernanda comenta lo siguiente:

...son conflictivos, son gente que escucha la radio a todo lo que da. No se respetan unos con otros, andan con insolencias, hay mucho... donde yo vivo hay mucho tráfico de droga, entonces uno no tiene mayor comunicación con los vecinos, porque ellos todavía creen que están en Valparaíso po. No respetan a nadie (Fernanda).

antiguamente en los cerros se vivía así... que no tienen limpio, ordenadito el patio, que se vea bonito, porque - si usted se fija - de la entrada para acá hay una casita, de la primera a la segunda casa, que está lleno de alfombras, lavadora afuera, así como chiquero. Chiquero le digo yo... picante, realmente picante. Yo digo no valorizan y teniendo un patio tan lindo y tiran toos' los cachureos pa'atrás así que lo encuentro feo (Elena).

Incluso, hay quienes atribuyen estas características a una particularidad de la vida en los cerros, una forma de comportamiento que se impregnaría en la vida de los sujetos, como si hubiera algo semejante a una "cultura de cerro" - en alusión a la cuestionada noción de "cultura de la pobreza" - que se transmite y se reproduce, casi automáticamente, entre quienes provienen de los cerros de Valparaíso. Elena comenta que "aquí hay mucha gente que se quedó pegá en el cerro", un estereotipo que suele utilizarse para etiquetar de forma generalizada a quienes provienen de tomas de terreno.

Mi pasaje po', es como un campamento, porque como que la gente igual no entiende que salimos del cerro y nosotros tenimos que hermosear nuestra villa, si ya no vivimos en el cerro, pero hay gente que no, es como que le da lo mismo agredir" (...) "a la gente le gusta vivir como vivía en los cerros (...) la gente como que quedó ahí po', o sea, como que le da lo mismo hermosear su casa, su lugar, es como que ellos siguen viviendo en el cerro (Carmen).

En este sentido, se interpreta que los habitantes de Villa El Aromo se enfrentan a una triple estigmatización socio-territorial vinculada a su condición social. Tres condiciones que los caracterizan y que son utilizadas como objeto de estigmatización y discriminación. En primer lugar, al provenir de Valparaíso, son estigmatizados como "porteños" o como "choros", conceptos que, aplicados peyorativamente, se asocian al carácter callejero o delictual. Segundo, al provenir de los cerros, son catalogados au- 
tomáticamente como "pobres" lo que, nuevamente, se asocia a actos delictivos, pero también a drogadicción y narcotráfico. Y tercero, al haber una gran cantidad de personas que provenían de asentamientos informales o tomas de terreno, son caracterizadas como sucias, desordenadas, violentas y conflictivas.

Cargar con estos estigmas, tanto internos como externos, dificulta la inserción de los damnificados en el nuevo territorio que habitan, lo que, sumado al trauma experimentado por la catástrofe, incrementa su percepción de daño y sufrimiento.

\section{Implantación de nuevas formas de sociabilidad barrial}

De acuerdo a los relatos de los entrevistados, el desplazamiento de los damnificados desde Valparaíso hacia Villa El Aromo ha significado una desarticulación de sus redes sociales, familiares y afectivas. La inserción en un territorio desconocido, en un conjunto habitacional con otras personas también desconocidas, se ha convertido, de esa forma, en una barrera para el surgimiento de la seguridad y la confianza entre vecinos.

Mi cerro, allá donde vivía, me gustaba porque era gente pobre, pero bien honrada. Igual tú eso lo echai de menos, porque yo igual acá llegué sin mi gente. Porque acá de mi cerro somos 4 familias las que llegamos y quedamos todas separás po'. Entonces, es como volver a conocer a otras personas, a hacerte otro ambiente, saber sobrevivir, porque hay que saber sobrevivir aquí en la villa (Carmen).

Nos alejamos poh. Es que nosotros teníamos una vida en Las Cañas, que estábamos rodeados de parientes y ejemplo, en mi caso, llegaban casi todos los niños. Nosotros teníamos siempre la casa con niños y se quedaban a dormir en la casa con nosotros. Íbamos a pasear. Más encima que podíamos dejar la casa sola y estaban los parientes cerca. Yo trabajaba, cuidaba niños también o cuidaba personas de tercera edad. Trabajaba en el mismo cerro, entonces me iba a la casa a almorzar, estábamos en más contacto. Y acá no poh, están todos los parientes de mi esposo en Valparaíso (Paola).

La sociabilidad barrial en Villa El Aromo se caracteriza, de acuerdo con el relato de los entrevistados, por los débiles lazos comunitarios, la inseguridad, la desconfianza y la individualización, lo que se traduce en un "saber sobrevivir" o, como nos comenta uno de nuestros entrevistados, en un "andar pisando con cuidado".

Al principio bien po', porque había tranquilidad. Pero empezaron a llegar más gente, más gente. Después, ya cuando llegó el tercer grupo, ya ahí quedó ya la embarrá acá, porque trajeron personas que, lamentablemente, no es tanto por el asunto económico, porque yo digo uno puede vivir en cualquier parte, estar bajo el puente, pero tener un sistema de vida, de saber 
vivir, es muy diferente. Y no tiene nada que ver con lo que uno tenga en el bolsillo y acá empezaron todos los problemas, todos los problemas, todos los problemas. Empezaron a robar, a golpearse, a meterse a las casas, a insultarse, a sacar armas, y la droga, portonazos, reventá de casas y yo, yo colapsé, nuevamente (...) yo lo único que quería era irme de aquí (Paola).

La violencia, el narcotráfico y los débiles lazos comunitarios constituyen aspectos fundamentales para la atomización de las redes vecinales. "Aquí la gente cada una vive su mundo", nos comenta una entrevistada. La misma agrega: "uno no se puede socializar mucho aquí", debido a que el día a día se vive con miedo.

Era un miedo, miedo, metiéndose todos en la casa, gente golpeándose, peleando a combos. Era una cosa de locos, sinceramente. Y hablan a todo volumen, con garabato de alto calibre y con armas y todo, disparando y yo quedé "plop". Yo sacaba por ejemplo acá afuera el escobillón, que termina de barrer, un paño y al otro día no estaba. Todo robándose, todo asaltándose. Era una cosa, pero de locos, de locos, de locos (Paola).

Esta nueva forma de sociabilidad barrial contrasta con sus formas pasadas de sociabilidad en los cerros de Valparaíso, que son descritas en torno a la colaboración, la confianza y las redes de apoyo vecinal. Estas transformaciones en sus formas de sociabilidad barrial contribuyen a incrementar la vivencia subjetiva de la relegación.

Mi vida igual ha cambiado mucho, mucho para mis hijas. Pero igual acá no soy feliz, porque mis hijas van creciendo y se supone que yo opté por una mejor vida para ellas, pero tu aquí vei cada cosa a veces. A veces, las niñas salen y tú tienes que entrarlas altiro porque se ponen a pelear. En cambio, en el otro cerro había pura gente conocida, entonces, no tenía miedo que los niños salieran a la calle a jugar. No teníai ese temor. Acá no conocís a nadie (Carolina).

A nivel de barrio, suele haber por parte de los entrevistados una percepción negativa de Villa El Aromo que remite, en gran medida, a los lazos vecinales. Se comienza a hablar de la inseguridad, de la violencia, del narcotráfico y del desconocimiento del otro, factores que, según señalan los entrevistados, no se encontraban en sus residencias anteriores en los cerros de Valparaíso. En otras palabras, la lógica del miedo y la inseguridad entre los vecinos de Villa El Aromo emerge en contraposición a las redes afectivas y de solidaridad descritas en Valparaíso.

En este sentido, no sólo hay una pérdida de redes de apoyo, sino que, además, hay una nueva forma de percibir las redes vecinales, basada en el conflicto, la desconfianza y la inseguridad. En consecuencia, el desplazamiento no solo genera alejamiento y fractura de las redes cotidianas de los sujetos desplazados, sino que, además, con su 
carácter nocivo de relegación $-\mathrm{y}$, como vimos a propósito de la demanda de apoyo psicológico, carente de acompañamiento- modela las relaciones vecinales en torno a las categorías mencionadas anteriormente, en referencia a Wacquant (2001), de la evitación mutua, la desconfianza, la elaboración de diferenciaciones simbólicas en sintonía con las "infra-diferencias" y el desvío del desprecio público hacia chivos expiatorios, en este caso, principalmente, hacia los habitantes vinculados a la droga.

Lo que nos parece fundamental destacar es que, Villa El Aromo, en tanto conjunto poblado mediante una operación estatal en el marco de un plan de reconstrucción, es el resultado de la acción del Estado y, en esa condición, los problemas descritos por los entrevistados dan cuenta de que este último actuó de forma desprolija, sin tener en consideración aspectos -o, como a veces se dice, "variables"- fundamentales, como el origen social, los sentimientos de pertenencia, las redes sociales y las fuentes de empleo, entre otras. De esta forma, un proceso tan complejo como la relocalización de habitantes damnificados queda reducido a la concentración de beneficiarios de subsidios habitacionales en conjuntos de vivienda, independientemente de sus complejas y particulares historias previas.

\section{Merma en el capital espacial}

Consideramos que la experiencia de relegación social derivada del tipo de vínculo establecido con las instituciones públicas y privadas y del tipo de relaciones interpersonales articuladas en el nuevo vecindario se acrecienta con la relegación urbana que experimentan los habitantes de Villa El Aromo. Nos referimos aquí, fundamentalmente, a la localización periférica de su actual vivienda respecto de la ciudad de Villa Alemana, y sus centros de servicios, pero también respecto de los lugares frecuentados en Valparaíso, ya que estos son considerados piezas clave de la experiencia espacial cotidiana de las y los damnificados.

Dicho con mayor precisión, para gran parte de los habitantes de Villa El Aromo, ser propietarios de una vivienda constituye un incremento en su calidad de vida respecto de su situación habitacional pasada, en la que muchos de ellos eran no-propietarios y habitaban viviendas precarias. Sin embargo y de acuerdo con sus relatos, Villa El Aromo es percibida como un emplazamiento que dificulta el desarrollo de sus actividades cotidianas. De hecho, la instalación en el nuevo espacio es vivida, inicialmente, como un proceso de desprovisión de servicios y de recursos. Esta percepción de relegación suele representarse en una constante comparación con su trayectoria habitacional en los cerros de Valparaíso, pues como señala una entrevistada, "acá todo es más difícil".

Visto desde esta perspectiva, el cambio a Villa El Aromo ha significado un desplazamiento hacia territorios alejados de sus hábitats originales, desprovistos de equipamientos, servicios y oportunidades laborales, lo que se ha traducido, a su vez, en el encarecimiento del costo de vida, dificultades para conseguir y desarrollar empleos, 
tanto en el mercado laboral formal como informal, incremento en los tiempos y costos de transporte, así como en el acceso a una reducida oferta de equipamientos, bienes y servicios. Una entrevistada nos comenta lo siguiente:

Por un lado, me siento contenta por lo que tengo y, por otro lado, me siento como triste...es como angustia porque no podís hacer too lo que yo hacía... pucha, no teníamos plata, bajábamos el cerro a pie... a veces no tenías para parar la olla y pucha, ibas donde vecinos que ya te conocían y te prestaban plata. O en el mismo negocio: "vecina, anóteme esto" y ya, arreglabai tu problema. Acá no conocís a nadie... nadie te dice: "aquí tienes cinco mil pesos para que tú cocines", porque son pocas las personas que te dicen sin recibir na. Entonces, mi marido allá tenía más opciones. Estaba el centro. Más opción de trabajo y todo más cercano. Acá no. Todo se me hace más difícil (Luisa).

El relato de esta entrevistada entrega evidencia respecto de que el cambio de emplazamiento ha significado una merma en su capital social, puesto que, cuando vivía en los cerros de Valparaíso podía recurrir a redes de confianza y apoyo mutuo entre vecinos para resolver sus necesidades básicas, como, por ejemplo, el abastecimiento del hogar. Asimismo, da cuenta de una merma en su capital espacial (Apaolaza et al., 2016), ya que, en Valparaíso, la cercanía a diversos equipamientos, bienes y servicios le permitía movilizarse a pie, ahorrando, además, los costos de movilización. A ello se suma la falta de oportunidades laborales y de posibilidades de desarrollar una economía informal en el nuevo espacio de vida, condicionando así sus redes de subsistencia. El relato de otra vecina reafirma este punto.

Se hace difícil aquí al no tener trabajo. Yo, por último, allá en el cerro donde yo vivía, por último, lavaba cobertores, hacía el aseo en las casas, cuidaba niños. Acá nada. Nada, nada, nada. Aquí qué voy a lavarles a los vecinos, si los vecinos están más mal que yo (Fernanda).

Asimismo, el desplazamiento hacia Villa El Aromo ha significado para sus habitantes un incremento en el costo de vida, así como también en los costos y tiempos de movilización cotidiana.

Acá la vida igual es más cara, es todo más caro. O sea, igual tengo más que antes porque sé que vivo mejor. O sea, no me lluevo, no vivo en el barro, en ese sentido, pero económicamente, no. Yo en Valparaíso yo trabajaba en el mercado. Entonces, yo bajaba con mil pesos al mercado. En cambio, de aquí pa' Valparaíso yo tengo que tener 2 mil pesos para bajar y ¿a qué hora? a las 3, 4 de la mañana tendría que irme. Yo igual vendo ropa, hago completos, igual me muevo pa' tenerle a mis hijos, ¿entiende?, pero acá es todo más caro, la vida aquí es muy cara (Carmen). 
Pese a que algunos habitantes de Villa El Aromo vivían en condiciones precarias de vivienda en los cerros de Valparaíso, la cercanía a servicios y equipamientos diversos, además de la variedad de medios de transporte y posibilidades de empleo, es comprendida como una forma de integración a la ciudad, lo que se ha perdido en su actual localización periférica en la ciudad de Villa Alemana. Al respecto, un vecino nos comenta que, "aparte de enviarnos a un lugar que no nos gusta, nos cambian de ambiente. Nos quitan lo poco y nada que tenemos" (Pedro).

Junto con ello, la percepción de relegación urbana y abandono del Estado se incrementa con la mala calidad constructiva de las viviendas y el entorno que habitan. Por ejemplo, como señalamos anteriormente, en 2014, a pocos meses de llegar a vivir a Villa El Aromo, las viviendas se inundaron tras las primeras lluvias del invierno. De acuerdo con el relato de los entrevistados, esta situación no se ha solucionado y se sigue repitiendo todos los años. Además, los vecinos comentan que las viviendas se están "hundiendo" por la mala calidad de los terrenos y que, hasta el momento, las autoridades no se han hecho cargo de esta situación, lo que es percibido como una forma de desatención, irresponsabilidad e, incluso, olvido.

Después la primera lluvia, acá como el barrial, haciéndose posas en los patios, se entró agua lluvia, por acá por la casa, tenemos la foto, corría el agua por acá, por aquí arriba en el entretecho, llegó el verano, se partió el patio en dos, se realizó una fisura de un lado a otro (Paola).

Son piscinas esto, porque las casas están bajo el nivel de calle, entonces no tienen salida (...) todos los que están aquí bajo el pasaje se inundan y aparte, han traído en su entorno la humedad...hongos y eso. Y lo otro, algo que usted no me va a creer, hay casas que se están hundiendo en milímetros. Hundiendo ¿Por qué? Porque son rellenos, no son terrenos compactados (Pedro).

\section{Conclusiones}

El objetivo de este artículo ha sido dar cuenta de las formas en las que viven y experimentan la relegación urbana habitantes que fueron relocalizados en la ciudad de Villa Alemana luego de resultar damnificados en el gran incendio de Valparaíso de 2014. El detalle puesto en los relatos de los entrevistados ha buscado entregar evidencia de primera mano respecto de cuatro dimensiones o aristas en que la relocalización experimentada ha actuado como amplificador del daño subjetivo provocado por el trauma del incendio y la pérdida total sufrida.

En efecto, nuestra propuesta ha sido mostrar la complejidad del daño subjetivo experimentado por individuos que, luego de la ocurrencia del incendio, podrían haber sido fácilmente descritos en función de una triple condición de vulnerabilidad: la de ser pobres, no-propietarios de vivienda y damnificados del incendio. Destacar este 
punto resulta sustantivo por cuanto pretendemos mostrar que no se trataba de rasgos escondidos o de dinámicas elusivas de las capacidades de descripción de la política pública, sino que, por el contrario, de características evidentes y bien conocidas por las y los profesionales que llevaron a cabo el proceso de reconstrucción y, de modo más general, completamente identificadas por los dispositivos de intervención pública operantes en el Chile actual.

En ese sentido, nuestra apuesta interpretativa ha sido mostrar que la relegación no es un efecto colateral, o no deseado, de la intervención post-desastres, sino que, más bien constituye un efecto previsible del operar de los mecanismos puestos en juego en las instancias de reconstrucción. Pero, además, hemos querido subrayar que esa relegación no implica solamente un posicionamiento espacial desventajoso, sino que, junto con ello, constituye una dinámica que genera estigmatización social, hostilidad y desconfianza hacia las instituciones, desarticulación del tejido social local y desprovisión de redes y recursos socio-territoriales. Es por eso que propusimos entender la dimensión subjetiva de la relegación en cuatro puntos, es decir, en términos de abandono del Estado, estigmatización socio-territorial, problemas de sociabilidad barrial y merma del capital espacial.

No obstante, hay un aspecto subjetivo que no hemos abordado de modo explícito, pero que, de distintas maneras, aparece de modo transversal en las entrevistas que realizamos. De hecho, en las citas que hemos presentado a lo largo de este texto solamente se insinúa, sin aparecer de manera completamente explícita. Se trata de un aspecto al que aludimos en nuestra revisión conceptual respecto de que el habitar en territorios de relegación desencadena una suerte de privación de los medios para hacer inteligible la propia experiencia.

Este punto, a la luz de la diversidad de citas presentadas, no resulta evidente. Pero es aquí donde resulta fundamental establecer un criterio de análisis que surge de la triangulación metodológica mediante la implementación de distintas técnicas de producción de información y nuestra labor de análisis progresiva y colectiva: nuestros entrevistados no tienen dificultades para encontrar responsables de su tragedia individual o colectiva. Tampoco tienen mayor problema en identificar diversas aristas que componen su situación problemática o, como le hemos llamado aquí, su situación de relegación. Sin embargo, tienen dificultades para dar impulso a su situación presente, para componer estrategias y modalidades de comprensión inter-subjetivas y para proyectar acciones conjuntas.

Es en estos puntos donde vemos plasmada la descripción de Wacquant (2001) en cuanto a que la situación de relegación tiene un efecto de desmoralización penetrante en los habitantes relocalizados. O, como planteamos citando a Lapeyronnie (2014), de que estos últimos experimentan una sensación de bloqueo a sus posibilidades de realización. En este sentido, quizá si la consecuencia subjetiva más profunda de la 
relegación en contextos post-desastre sea la dificultad de producir un nuevo sentido para reinstalar las capacidades de agencia colectiva y proyectar la acción común. Ciertamente y como ha sido observado en otros casos de reconstrucción (Larenas et al., 2015; Rojas y Sandoval, 2020), las dificultades experimentadas en el proceso no determinan sus posibilidades para rearticular sus capacidades de agencia, señalándose que no es un proceso totalmente clausurado. Sin embargo, como ha sido observado en este caso, las posibilidades y márgenes de acción de la población damnificada se tornan altamente restrictivas, más en un contexto sumamente neoliberal como el chileno.

La situación en que quedaron los damnificados del incendio de Valparaíso 2014 no puede ser resuelta a través de la entrega de una vivienda en propiedad, o con un conjunto de bienes (ropa, enseres, artefactos) subsidiados por el Estado. Hay dimensiones profundas, que exigen abordajes y tratamientos específicos, que no están siendo consideradas, a pesar de que los dispositivos de la política pública tienen conocimiento de ellos.

Este tratamiento inadecuado de la complejidad, variedad y profundidad del daño sufrido por personas afectadas por una catástrofe tiene una consecuencia simbólica menos evidente: al operar en el marco de un paradigma de reconstrucción neoliberal y viviendista, las necesidades y requerimientos subjetivos que aquí hemos esbozado corren el riesgo de aparecer como inadecuados e improcedentes. Vale decir, la propia experiencia de daño y las necesidades de asistencia para enfrentarlas pueden ser etiquetadas como ilegítimas por parte de los poderes públicos encargados de la reconstrucción. Sólo que, si la secuencia explicativa que hemos avanzado en este texto es plausible, dicha ilegitimidad puede comenzar a aparecer también del lado de los propios damnificados, como violencia simbólica y auto-estigmatización, instalando una arista extremadamente compleja para la comprensión de estas dinámicas psicosociales, pero también y, sobre todo, para la intervención política que busca solucionarlas.

\section{Referencias}

Angelcos, N., Campos, L., Ropert, T., y Sharim, D. (2020). De protagonistas a denegados: el doble trauma en un caso de relocalización post-incendio en Valparaíso, Chile. Scripta Nova, 24 (636).

Apaolaza, R., Blanco, J., Lerena N., López-Morales, E., Lukas, M., y Rivera, M. (2016) "Transporte, desigualdad social y capital espacial: análisis comparativo entre Buenos Aires y Santiago de Chile". Revista ICONOS, 56, 19-41.

Blanco, J., Bosoer, L., y Apaolaza, R. (2014). "Gentrificación, movilidad y transporte: aproximaciones conceptuales y ejes de indagación". Revista de Geografía Norte Grande, 58, 41-53 
Blanco, J., y Apaolaza, R. (2016). "Políticas y geografías del desplazamiento. Contextos y usos conceptuales para el debate sobre gentrificación”. Revista INVI, 31(88), 73-98.

Borsdorf, A., Sánchez, R., y Marchant, C. (2008). “Aprendiendo de los errores. La necesidad de cambios a la política nacional de vivienda en ciudades intermedias chilenas". Actas del X Coloquio Internacional de Geocrítica, Universidad de Barcelona. Recuperado de http://www.ub.es/geocrit/-xcol/166.htm.

Bourdieu, P. (1992). Réponses : pour une anthropologie réflexive. París: Editions du Seuil.

Bourdieu, P. (2001). Las estructuras sociales de la economía. Buenos Aires: Manantial.

Butler, J., y Athanasiou, A. (2017). Lo performativo en lo político. Madrid: Eterna Cadencia.

Campos, L., Suazo, V., y Cárdenas, A. (2018). Aceleración, desplazamiento, relegación: aportes para comprender el capitalismo chileno posdesastre. Bitácora Urbano Territorial, 28(2), 45-52.

Concha-Saldías, C., Micheletti, S., Olivares-Larraín, R., y Rasse, A. (2015). "Reconstrucción post-terremoto en la ruralidad del Maule”. Bitácora Urbano Territorial, 1 (25), 89-98.

Contreras, Y., y Arriagada, C. (2016). "Reconstrucción exclusionaria. Lo comunitario y las políticas públicas en ciudades menores e intermedias chilenas afectadas por el terremoto y tsunami del 27F 2010: los casos de Constitución y Dichato". Revista de Geografía Norte Grande, 64, 83-107.

Contreras, Y., y Beltrán, M. (2015). "Reconstruir con capacidad de resiliencia: el casco histórico de la ciudad de Constitución y el sitio del desastre del terremoto y tsunami del 27 de febrero 2010”. Revista INVI, 30 (83), 79-115.

Delgadillo, V. (2015). "Desafíos para el estudio de desplazamientos sociales en los procesos de gentrificación”. Madrid: Contested_Cities. Recuperado dehttp://contested-cities.net/wp-content/uploads/sites/8/2015/01/WPCC-15002-DelgadilloVictor_DesafiosEstudioDesplazamiento.pdf.

Ducci, M. (1997). “Chile: el lado obscuro de una política de vivienda exitosa”. Eure, 23 (69), 99-115.

Inzulza, J., y Cárdenas, A. (2017). “Desplazamiento subsidiario: efectos de gentrificación contemporánea en barrios céntricos en reconstrucción post-terremoto. El caso de Talca, Chile”. Cuadernos GeográFicos, 56 (3), 268-291.

Janoschka, M. (2016). “Gentrificación, desplazamiento, desposesión: procesos urbanos claves en América Latina”. Revista INVI, 31 (88), 27-71. 
Klein, N. (2007). Doctrina del shock: el auge del capitalismo del desastre. Barcelona: Paidós.

Lapeyronnie, D. (2014). "L'économie morale de la discrimination. La morale des inégalités dans les banlieues populaires françaises”. En Inégalités et justice sociale (pp. 79-93). Paris: La Découverte.

Larenas, J., Salgado, M., y Fuster, X. (2015). "Enfrentar los desastres socionaturales desde los capitales y recursos comunitarios: el caso de la erupción volcánica de Chaitén, Chile”. Magallania, 43(3), 125-139.

Letelier, F., y Boyco, P. (2011). Talca pos-terremoto: una ciudad en disputa. Modelo de Reconstrucción, Mercado Inmobiliario y Ciudadanía. Santiago: Ediciones SUR.

Micheletti, S., Opazo, J., Rodríguez, C., Spuler, E., y Ríos, T. (2017). “Relocalización pos terremoto. Trayectorias migratorias en damnificados rurales de la Región del Maule". Pensamiento y Acción Interdisciplinaria, 3(1), 106-122.

MINVU (Ministerio de Vivienda y Urbanismo). (2014). Plan de inversiones, reconstrucción y rehabilitación urbana. Ministerio de Vivienda y Urbanismo, Gobierno de Chile.

MINVU (Ministerio de Vivienda y Urbanismo). (2016). Reporte plan de inversiones incendio de Valparaíso. Santiago de Chile: Ministerio de Vivienda y Urbanismo.

Micheletti, S., y Letelier, F. (2016). "Damnificados de la reconstrucción post-terremoto. Efectos del modelo en el hábitat rural del Maule”. Revista INVI, 31(86), 17-58.

Rasse, A., y Letelier, F. (2013). "El proceso de reconstrucción de viviendas en el centro de Talca: fotografía a dos años de la catástrofe”. Revista INVI, 28 (77), 139-164.

Reyes, M., Arensburg, S., y Póo, X. (Coordinadoras). (2016). Vidas Cotidianas en Emergencia: Territorios, Habitantes y Prácticas. Santiago: Social Ediciones.

Rivera, H., y Campos, L. (2019). “Maestros de la construcción. Protagonistas subalternos del proceso de reconstrucción de los cerros de Valparaíso en Chile”. Sociedad y economía, (37), 114-130.

Rodríguez, A., y Sugranyes, A. (2004). "El problema de vivienda de los "con techo"”. Eure, 30 (91), 53-65.

Scribano, A. (2007). Mapeando Interiores. Cuerpo, Conflicto y Sensaciones. Córdoba, Argentina: Universitas.

Rojas-Páez, L., y Sandoval-Díaz, J. (2020). “Habitando 'no lugares': subjetividad y capacidades familiares ante un desastre socionatural en Chile”. Íconos. Revista de Ciencias Sociales, 66, 59-80.

Suazo, V. (2019). "Economía política del desastre: gentrificación en Talca post-terremoto de 2010". Revista CIS, 16 (27), 69-85. 
Theodore, N., Peck, J., y Brenner, N. (2009). "Urbanismo neoliberal: la ciudad y el imperio de los mercados". Temas Sociales, 66, 1-11.

Wacquant, L. (2001). Parias urbanos. Marginalidad en la ciudad a comienzos del milenio. Buenos Aires: Manantial.

\section{Sobre los autores}

Luis Campos Medina es profesor asociado en la Universidad de Chile. Es sociólogo por la Universidad de Chile y doctor en sociología por la EHESS de Francia. Correo Electrónico: luiscampos@uchilefau.cl. (iD) https:/ / orcid.org/0000-0002-5157-4974

Víctor Suazo Pereda es arquitecto por la Universidad de Chile, cuenta además con estudios de Magíster en Desarrollo Urbano, Pontificia Universidad Católica de Chile y Diplomado en Derecho a la Ciudad y Producción Social del Espacio, Universidad Alberto Hurtado. Correo Electrónico: victor.suazo@ug.uchile.cl.

(D) https:/ / orcid.org/0000-0002-9319-0709

Andrea CÁrdenas Piñero es arquitecta por la Universidad de Chile, cuenta además con estudios de Magíster en Desarrollo Urbano, Pontificia Universidad Católica de Chile. Correo Electrónico: acardenas@territorio.cl. iD https://orcid.org/00000003-3619-1294 


\title{
CUHSO
}

Fundada en 1984, la revista CUHSO es una de las publicaciones periódicas más antiguas en ciencias sociales y humanidades del sur de Chile. Con una periodicidad semestral, recibe todo el año trabajos inéditos de las distintas disciplinas de las ciencias sociales y las humanidades especializadas en el estudio y comprensión de la diversidad sociocultural, especialmente de las sociedades latinoamericanas y sus tensiones producto de la herencia colonial, la modernidad y la globalización. En este sentido, la revista valora tanto el rigor como la pluralidad teórica, epistemológica y metodológica de los trabajos.

\author{
EDITOR \\ Matthias Gloël \\ COORDINADORA EDITORIAL \\ Claudia Campos Letelier \\ CorReCTOR DE ESTILO Y DISEÑADOR \\ Ediciones Silsag \\ Traductor, CORRECTOR LENGUA INGLESA \\ Aurora Sambolin Santiago \\ SITIO WEB \\ cuhso.uct.cl \\ E-MAIL \\ cuhso@uct.cl
}

LICENCIA DE ESTE ARTÍCULO

Creative Commons Atribución Compartir Igual 4.0 Internacional 